\title{
The Thespian Client: The Benefits of Role-playing Teaching Techniques in Psychology
}

\author{
Sean Issac Gibbs \\ Department of Psychology, Dillard University, New Orleans, Louisiana \\ Email address: \\ sigibbs@dillard.edu \\ To cite this article: \\ Sean Issac Gibbs. The Thespian Client: The Benefits of Role-playing Teaching Techniques in Psychology. American Journal of Applied \\ Psychology. Vol. 8, No. 5, 2019, pp. 98-104. doi: 10.11648/j.ajap.20190805.12
}

Received: September 26, 2019; Accepted: October 12, 2019; Published: October 23, 2019

\begin{abstract}
Role-playing teaching techniques in psychology allows students the opportunity to practice the skills of a psychologist and examine mental health disorders in person. This technique simulates scenarios that students may face in their careers by creating fictional clients and role-playing situations solidifying professional therapeutic skills. Multiple studies have established the benefits of using student actors to play the role of "client" while allowing psychology students to play the role of "psychologist". The purpose of this study is to examine the process of developing and implementing a role-playing learning project. A literature review was conducted examining the benefits and barriers of role-playing teaching techniques. The article describes how role-playing teaching techniques reinforce theories and skills taught to psychology students and increases their knowledge base through this simulated experience. Recommendations for creating a successful role-playing project are explored and a program curriculum template based on the study's findings is provided. Future research implications of advance quantitative experimental studies are suggested to explore the overall effectiveness of the training project.
\end{abstract}

Keywords: Role-Playing, Teaching Techniques, Psychology and Theater Arts Students

\section{Thespians Make Great "Clients"}

Role-playing is one of the more effective teaching techniques used for training professional therapeutic skills to undergraduate psychology students $[4,14,15,19]$. In role-playing activities, students are asked to depict an individual suffering from a psychological disorder. Typically, one student plays the role of the client suffering from the disorder while another student conducts a clinical interview, completes a biopsychosocial assessment, or demonstrates a therapeutic intervention. Practicing these skills and observing live client behavior reinforces traditional educational programming. Unfortunately, psychology students lack the dramatic talent or desire to convincingly portray a client suffering from mental illness [6, 19].

In the area of theater arts, role-playing is an unscripted improvisational technique that is used to aid in developing a character for live performances. In role-playing activities, student actors play the part of fictional characters in an imaginary world that is organized, adjudicated, and sometimes created by a game master (e.g., a narrator, referee, professor) [4]. In order for a role-playing scene to be successful, the student actors must collaborate to construct the scene and story [4]. Actors, particularly theater arts students, benefit from improvisational acting opportunities. Successful teaching and learning is gained through providing actors with a series of experiences that allows them to practice attention and response $[22,24]$. Theater arts students are assigned the task of crafting and taking on the identity of characters; character refers to the true essence of an individual [8]. "An actor takes on or transforms into the identities of characters by assuming or portraying the individual's characteristics, that is: age, gender, weight, nationality, value systems, and connecting to the truth of the individual as revealed through their actions in the story [8]." Theater arts students, generally, are not required to take courses in the area of psychology, but it is credible that they can benefit. In Wolf and Miller's research, they discuss that actors are responsible for answering and enacting the question of "Who are you?" Psychologists analyses the "why." Theater arts students are trained to master the art of acting, therefore it is reasonable for them to deliver a better/ more convincing performance in a role-playing activity than psychology students. In Pomerantz' research, he states, "In the worst-case scenario, poor acting on 
the part of "the client" (psychology students) can cause the dyad to deteriorate into a series of gaffes or awkward silences in which little meaningful learning takes place [19]."

\section{Interdisciplinary Learning}

The collaboration between psychology and theater arts students is beneficially reciprocated. Both fields of study focus on human behavior, therefore, it is reasonable for psychology and theater arts students to engage in interdisciplinary learning. Unfortunately, in most academic psychology and theater arts programs, there is limited documented evidence of having incorporated a curriculum that reflects collaborative learning models to simultaneously educate both areas of study. The connected and partnership learning models are most effective in integrating the studies of psychology and theater arts. The connected learning model is an approach where content from one subject area is used to enhance or complement the educational experience in another subject area [7]. The partnership learning model provides a strategy for complex unification of content from two or more subject areas [7].

Interdisciplinary learning is an instructive process where multiple subject areas are integrated to promote enhanced learning in each subject area [7]. Multiple studies have described the prolific benefits of interdisciplinary learning in the academic programs of psychology and theater arts $[11,12$, 15-17, 19, 23]. Psychology and theater arts share the commonality of analyzing behavior. A partnership between these fields of study is appropriate and has the potential of maximizing the students' educational growth in preparation for their respective careers.

\section{Method}

\subsection{Differences in Research}

A comprehensive literature review on collaborating theater arts and psychology departments through role-playing teaching techniques reveals that there is a lack of information about the development and implementation of this activity. The limited research on the subject matter is discussed in a few articles ("Actors in the Classroom: The Dramatic Pedagogy Model of Counselor Education," "Creativity in Teaching Case Conceptualization Skills: Role-play to Show the Interconnectedness of Domains," "Using Actors as 'Clients' for an Interviewing Simulation in an Undergraduate Clinical Psychology Course" and "Who Plays the Client? Collaborating with Theater Departments to Enhance Clinical Psychology Role-Play Training Exercises") where they discussed how to collaboratively use the role-play teaching technique in psychology and theater arts $[6,14,15,19]$.

Clarke, Binkley, \& Andrews' Dramatic Pedagogy Model (DPM) is described as a role-playing collaborative teaching tool where trained actors are used to play the role of clients in order to assist in the development of specific counseling skills [6]. DPM heavily focuses on the identification and preparation of the actors to promote a productive learning environment. Clarke, Binkley, \& Andrews suggest that the theatre faculty and students must have a strong sense of commitment to the project and be willing to review training material in preparations for the role. These collaborative screening and preparation process is described as an essential component to the success of the project.

Hinkle and Deans' research creates a role-play exercise where students take on the perspective of various case conceptualization domains (e.g., client history, presenting problem, culture, resources) and interact with one another while in their respective roles. The students divide into groups of five or six and they are given cue cards with a portion of a fictitious client's psychosocial history. The group members act out their respective cue cards and simultaneously interact with one another. The goal of the assignment is for students to gain a more holistic understanding of a client and learn how different parts of a client's psychosocial history can influence and create a larger client story [14].

Pomerantz elaborates on the recruitment process of the student actors, and he discusses the benefits of role-playing with actors opposed to psych students. In Pomerantz' experiment; he uses multiple components in the recruitment process. Pomerantz utilized his campus' theater department independent-study course as a vehicle to recruit potential student actors. He also used other recruitment efforts such as: email lists, flyers, campus newspaper advertisements, and public speaking engagements. This article addresses the benefits, barriers, development and implementation of a role-playing teaching activity using theater arts students as clients [19].

Lane's research formulates a structure to a curriculum for a 4-week psychology course. The research goes into the details of how to incorporate role-playing into a curriculum, but it does not explore the benefits of the role-playing experience. In Lane's experiment, she utilizes 4 student actors and 16 psychology students over the course of 4 weeks. The 16 psychology students are divided into groups of 4 , and the 4 groups are paired off with the 4 student actors. Over the course of 3 weeks, the psychology students take turns playing the role of "psychologist" in 20 minute duration role-play sessions [15].

\subsection{Benefits of Role-Play}

There is evidence to support the benefits of successful role-play collaboration between theater arts and psychology departments. The role-playing teaching technique is used in a classroom setting to engage students and to reinforce the theories and skills taught in class [21]. Psychology students are able to increase their knowledge of abnormal psychology and counseling skills through their role-playing experience. In most cases, particularly in undergraduate studies, very few students have had an opportunity to observe a live clinical session. Participating in role-playing and observing other students' role-play provides the unique opportunity to gain insight on their respective careers. 


\subsubsection{Therapeutic Skills}

Traditionally, education for undergraduate psychology students focuses on theoretical practice and concepts oppose to application. The role-playing teaching technique gives students the opportunity to develop the therapeutic skills of active listening and empathy. Typically, these skills are developed when working with real clients in a graduate studies program or in a training program for professional psychologists. Undergraduate students rarely get the opportunity to develop the therapeutic skills of active listening and empathy. Rodríguez, López, Escolano, García-Grau, García, Fort, Lluch, and Pros' research reveal that training programs for clinical and health psychologists enable trainees to develop the therapeutic skills that have been shown to make a positive contribution to treatment outcomes [21]. With this in mind, an awareness of one's own resources and limitations (both personal and professional); the ability to regulate one's emotions, and to engage in empathy and active listening can be regarded as core skills for a range of healthcare professions. Their development should be observed as a priority in the corresponding training programs $[3,5,9,10,18]$. The evidence-based teaching method of role-playing promotes the learning of skills and prepares psychology students for their professional careers.

\subsubsection{Empathic Understanding}

Students experienced a significant decrease in emotional distance between themselves and those with mental disorders through the role-playing experience [20]. Providing psychology students the opportunity to experience the emotional and mental trajectory of a specific psychiatric disorder, through role play can assist in developing altered attitudes towards mentally ill patients and increases the students' empathic capacity simultaneously [21].

\subsection{Barriers of Role-Play}

Several barriers exist to create a successful role-playing activity using theater arts majors. The most prevalent barrier is the synchronization between the psychology and theater arts departments. Every department has interdepartmental responsibilities and is accountable to the students. Most departmental academic calendars are filled at the beginning of the school year, and instructors (particularly departmental heads) are bombarded with responsibilities and deadlines. Many professors have the desire to collaborate, but when asked to commit to the project they simply do not have the time or is unable to synchronize with the differing department.

\subsubsection{Administration Problems}

Pomerantz' research addresses the issue of how to secure actors for the role-playing activity. Pomerantz suggests that psychology departments should collaborate with theater arts faculty to offer course credit to actors. This would require the theater department to add an additional course or elective to their requirements. However, the ultimate decision on whether or not the suggestion would be adopted depends upon the administration of the college or university.

\subsubsection{Fiscal Limitations}

Fiscal restrictions are a major barrier in collaborating between the psychology and theater arts departments. Research suggest paying student actors a fee (of minimum wage) to participate in role-playing experiments increases the individual's commitment to the project $[6,15]$. Compensating student actors is beneficial, but it is not always practical. Many psychology departments have limited funding, and grants may not be available or renewable [19].

Soliciting volunteer student actors is an effective measure to counter departmental fiscal restrictions. However, there is no incentive for theater arts students to be consistent in their participation of the experiment [19]. Overall, the greatest barrier of successfully creating role-play collaboration between theater arts and psychology departments is securing reliable and consistent student actors.

\section{Result}

\subsection{A Theoretical Curriculum}

Based on the researcher findings, a theoretical curriculum for successful role-play collaboration between undergraduate psychology and theater arts departments is described below. The literature review provides evidence of the benefits of a role-play collaboration; the advantages are significant for both psychology and theater arts students. However, this curriculum examines undergraduate psychology departments of a college or university. The objective of the role-playing teaching technique is to provide psychology students with an opportunity to: (1) observe live client behavior; (2) practice conducting clinical interviews; (3) perform biopsychosocial assessments; (4) demonstrate therapeutic intervention, and (5) learn the therapeutic skills of active listening and empathy.

The role-playing collaboration experiment consists of a test group of 24 undergraduate psychology students and 6 theater arts students with improvisational acting experience. The psychology students are assigned the role of "clinician," and the theater arts students are assigned the role of "client." The setting of the experiment is within the confinement of an upper-level undergraduate psychology course. The experiment is conducted within the period of a 16-week semester psychology class that meets three times a week for 50 minutes.

Within week 3 of the experimental semester, 6 volunteer student actors are recruited and given cue cards with a name and description of a psychological disorder that includes the client's age, sex, symptoms, family history, medical history, and education etc. The student actors consult with the instructor to discuss their characters' diagnosis, background, behavior and subtle idiosyncrasies. After the initial meeting between the student actors and instructor, the theater arts students independently prepare their roles. The theater arts students are encouraged to contact the instructor for questions and clarity concerning their respective characters. The student actors have 8 weeks to prepare and work out the details of their roles. 
During the first 8 weeks of the experiment, while the theater arts students independently study, the psychology students are receiving classroom instruction and are completing class assignments on theoretical practice and psychology concepts. During week 11 of the semester, the psychology students are given a template for a clinical interview and a biopsychosocial assessment. During this week, the instructor devotes three classes to teaching the students how to complete a clinical interview and a biopsychosocial assessment.

The actual role-playing assignment occurs during weeks 11, 12,13 , and 14 . The 24 psychology students are divided into 4 groups. Group 1 completes their role-playing exercise during week 11; group 2 completes their exercise on week 12, group 3 completes their exercise on week 13; and group 4 completes their exercise on week 14. The six volunteer theater arts students are only required to attend two class sessions, but are invited to observe their peers' role-playing session. Each role-playing session is approximately 25 minutes long. The psychology students conduct their clinical interviews, perform biopsychosocial assessments, demonstrate therapeutic intervention, and demonstrate the therapeutic skills of active listening and empathy within the 25 min role-playing session. Each student actor must participate in two classes, two (back to back) role-playing sessions for the duration of 50 minutes per class setting. The student actors are responsible for acting out four different scenarios: two scenarios in the first class and two in the second class.

During week 15, the instructor and the psychology students discuss the overall experience of the role-playing exercise, and the students' complete evaluations and a posttest survey of their learning experience.

\subsection{Instruments}

\subsubsection{Fictional Client Development}

Research suggests that the client's descriptions should have sufficient information to create a realistic character, but to avoid developing a script [21]. Basic demographic information, history, symptoms and diagnostic presentation are provided to the actors. This limited information allows the actors to maintain the spontaneity of a real life assessment, while limiting the risk of projecting their own emotions into the case. Abnormal psychology textbooks, diagnostic casebooks, or actual client data can be used in the creation of fictional clients when identifying information is changed or removed from the description. An example of a fictional character description template is provided below in Table 1 (see appendix).

\subsubsection{Assignment Procedure}

The course assignments objectives and structure can be altered based on the students' level of experience and course requirements. Assignment objectives can range from learning how to conduct a clinical interview, complete a biopsychosocial assessment, or to demonstrate a therapeutic intervention. Research suggest that undergraduate students may not have experience working directly with clients and assignments would yield better results if the cases presented were of mild-to-moderate in symptom severity $[6,15]$. This would suggest that performing initial screenings and developing clinical interview skills might be better-suited assignments for undergraduate students. The researcher has developed an assignment template in Tables 2 and 3 below (see appendix).

\subsubsection{Student Evaluations}

Student performance evaluations can be assessed through a number of measurement including; grading rubrics, written exams, instructor subjective rating, self-report surveys, or reflection papers. Research suggests that the evaluation process reflects the students' skill level and objective of the assignment [13]. Qualitative data can also be collected to describe the actors and students' experience. According to Pomerantz findings, "students considered the method a positive educational experience that enhanced learning...the most frequently cited strength was the hands-on experience [19]." Analyzing the quantitative and qualitative data from the assignment can provide additional benefits to the students learning outcomes and provided future research implication.

\section{Discussion}

A comparison of different role-playing teaching techniques reveals common suggestions and limitations. Research findings indicate that the experiential component of a role-play teaching technique allows students to learn about client symptoms in a safe environment. The recruitment and training of actors is also viewed as essential to the overall success of a role-play teaching activity. Interventions and strategies are provided to meet learning objectives.

Although, research findings indicate that collaboration between the psychology and theater arts departments is a vital component to the effectiveness of a role-play teaching project; many of the studies suggest that it is also a major limitation [6, $15,19,21]$. The challenges of coordinating schedules, screening participates, and developing interdisciplinary curriculum requires commitment to achieve the project's learning objectives. Securing funding sources to support the project can reassure active engagement from involved parties (e.g. compensating participants, offering release time to faculty, paying conference and/or research associated fees).

The limited research on the role-play teaching technique in psychology creates a challenge for evaluating its effectiveness. In future studies, quantitative research focused on experimental manipulation of different variables (e.g. mild to severe client symptoms, professional or educational level of experience, performance on written exams, control groups, etc.) can provide concrete evidence of the program's effectiveness.

\section{Conclusion}

Research findings support the benefits of role-play collaboration training between theater arts and psychology departments. Role-playing teaching technique reinforce the 
theories and skills, increase understanding of different mental health disorders, and improve empathy in psychology students through stimulated experience. However, struggles collaborating between the psychology and theater arts departments require thorough planning and commitment from both departments. Based on the research findings, it is beneficial to develop collaborative curriculum planning a semester before the program implementation. This provides an opportunity to secure administration approval to offer course credits and it secures financial support for the program to reduce accountability and recruiting issues. The theoretical curriculum described is a suggested guideline for curriculum planning between the undergraduate psychology and theater arts departments. The curriculum and assignments can be altered to meet the instructor, student, or programs' need with minor changes.

\section{Acknowledgements}

I would like to express my appreciation and thanks to the Dillard University School of Sciences faculty and staff for their support in this endeavors. I would also like to acknowledge the handwork and dedication of Victoria Robertson and Jayna L. Parker.

\section{Appendix}

Table 1. Fictional Client Description.

\begin{tabular}{ll}
\hline Fictional Client Description \\
\hline Instructions: & Read the fictional client description below. Develop you own backstory about the client, his or her motives and how they cope with \\
their presenting problem.
\end{tabular}

Table 2. Intake Screening Assignment.

\begin{tabular}{|c|c|}
\hline \multicolumn{2}{|c|}{ Intake Screening Assignment } \\
\hline \multicolumn{2}{|c|}{$\begin{array}{l}\text { Instructions: Actors will play the role of a client suffering from a mental health disorder. Students will conduct a clinical interview with the actor and } \\
\text { complete the attached intake screening form. Students'scores are based on their ability to build rapport with the client, collect relevant information and } \\
\text { develop a preliminary diagnostic impression. The intake screening is a guideline for the clinical interview and should not be used as a self-report } \\
\text { measure. Ask the client follow-up questions to collect relevant data to develop your diagnostic impression. }\end{array}$} \\
\hline \multicolumn{2}{|c|}{ Intake Screening Form } \\
\hline Name: & Date: \\
\hline Age: & Date of Birth: \\
\hline Gender: & Sexual Orientation: \\
\hline \multicolumn{2}{|c|}{ Presenting Problems: } \\
\hline \multicolumn{2}{|l|}{ History: } \\
\hline \multicolumn{2}{|c|}{ Psychiatric: } \\
\hline \multicolumn{2}{|c|}{ Medical: } \\
\hline \multicolumn{2}{|c|}{ Substance Use: } \\
\hline \multicolumn{2}{|c|}{ Family: } \\
\hline Social: & \\
\hline
\end{tabular}

Table 3. Symptom Checklist.

\begin{tabular}{|c|c|c|c|c|c|}
\hline \multicolumn{6}{|l|}{ Symptom Checklist } \\
\hline \multicolumn{6}{|c|}{$\begin{array}{l}\text { Instructions: For each question, circle the number that best describes how much (or how often) the client has reported being bothered by each } \\
\text { problem during the past TWO (2) WEEKS. }\end{array}$} \\
\hline & $\begin{array}{l}\text { None } \\
\text { Not at all }\end{array}$ & $\begin{array}{l}\text { Slight Rare, less } \\
\text { than a day or two }\end{array}$ & $\begin{array}{l}\text { Mild Several } \\
\text { days }\end{array}$ & $\begin{array}{l}\text { Moderate More than } \\
\text { half the days }\end{array}$ & $\begin{array}{l}\text { Severe Nearly } \\
\text { every day }\end{array}$ \\
\hline I. Little interest or pleasure in doing things? 01234 & 0 & 1 & 2 & 3 & 4 \\
\hline 2. Feeling down, depressed, or hopeless? & 0 & 1 & 2 & 3 & 4 \\
\hline $\begin{array}{l}\text { 3. Feeling more irritated, grouchy, or angry than } \\
\text { usual? }\end{array}$ & 0 & 1 & 2 & 3 & 4 \\
\hline
\end{tabular}




\begin{tabular}{|c|c|c|c|c|c|}
\hline \multicolumn{6}{|l|}{ Symptom Checklist } \\
\hline \multicolumn{6}{|c|}{$\begin{array}{l}\text { Instructions: For each question, circle the number that best describes how much (or how often) the client has reported being bothered by each } \\
\text { problem during the past TWO (2) WEEKS. }\end{array}$} \\
\hline & $\begin{array}{l}\text { None } \\
\text { Not at all }\end{array}$ & $\begin{array}{l}\text { Slight Rare, less } \\
\text { than a day or two }\end{array}$ & $\begin{array}{l}\text { Mild Several } \\
\text { days }\end{array}$ & $\begin{array}{l}\text { Moderate More than } \\
\text { half the days }\end{array}$ & $\begin{array}{l}\text { Severe Nearly } \\
\text { every day }\end{array}$ \\
\hline $\begin{array}{l}\text { 4. Sleeping less than usual, but still have a lot of } \\
\text { energy? }\end{array}$ & 0 & 1 & 2 & 3 & 4 \\
\hline $\begin{array}{l}\text { 5. Starting lots more projects than usual or doing } \\
\text { more risky things than usual? }\end{array}$ & 0 & 1 & 2 & 3 & 4 \\
\hline $\begin{array}{l}\text { 6. Feeling nervous, anxious, frightened, worried, or } \\
\text { on edge? }\end{array}$ & 0 & 1 & 2 & 3 & 4 \\
\hline 7. Feeling panic or being frightened? & 0 & 1 & 2 & 3 & 4 \\
\hline 8. Avoiding situations that make you anxious? & 0 & 1 & 2 & 3 & 4 \\
\hline $\begin{array}{l}\text { 9. Unexplained aches and pains (e.g., head, back, } \\
\text { joints, abdomen, legs)? }\end{array}$ & 0 & 1 & 2 & 3 & 4 \\
\hline $\begin{array}{l}\text { 10. Feeling that your illnesses are not being taken } \\
\text { seriously enough? }\end{array}$ & 0 & 1 & 2 & 3 & 4 \\
\hline 11. Thoughts of actually hurting yourself? & 0 & 1 & 2 & 3 & 4 \\
\hline $\begin{array}{l}\text { 12. Hearing things other people couldn't hear, such } \\
\text { as voices even when no one was around? }\end{array}$ & 0 & 1 & 2 & 3 & 4 \\
\hline $\begin{array}{l}\text { 13. Feeling that someone could hear your thoughts, } \\
\text { or that you could hear what another person was } \\
\text { thinking? }\end{array}$ & 0 & 1 & 2 & 3 & 4 \\
\hline $\begin{array}{l}\text { 14. Problems with sleep that affected your sleep } \\
\text { quality over all? }\end{array}$ & 0 & 1 & 2 & 3 & 4 \\
\hline $\begin{array}{l}\text { 15. Problems with memory (e.g., learning new } \\
\text { information) or with location }\end{array}$ & 0 & 1 & 2 & 3 & 4 \\
\hline (e.g., finding your way home)? & 0 & 1 & 2 & 3 & 4 \\
\hline $\begin{array}{l}\text { 16. Unpleasant thoughts, urges, or images that } \\
\text { repeatedly enter your mind? }\end{array}$ & 0 & 1 & 2 & 3 & 4 \\
\hline $\begin{array}{l}\text { 17. Feeling driven to perform certain behaviors or } \\
\text { mental acts over and over again? }\end{array}$ & 0 & 1 & 2 & 3 & 4 \\
\hline $\begin{array}{l}\text { 18. Feeling detached or distant from yourself or your } \\
\text { physical surroundings? }\end{array}$ & 0 & 1 & 2 & 3 & 4 \\
\hline $\begin{array}{l}\text { 19. Not knowing who you really are or what you } \\
\text { want out of life? }\end{array}$ & 0 & 1 & 2 & 3 & 4 \\
\hline $\begin{array}{l}\text { 20. Not feeling close to other people or enjoying } \\
\text { your relationships with them? }\end{array}$ & 0 & 1 & 2 & 3 & 4 \\
\hline $\begin{array}{l}\text { 21. Drinking at least } 4 \text { drinks of any kind of alcohol } \\
\text { in a single day? }\end{array}$ & 0 & 1 & 2 & 3 & 4 \\
\hline $\begin{array}{l}\text { 22. Smoking any cigarettes, a cigar, or pipe, or using } \\
\text { snuff or chewing tobacco? }\end{array}$ & 0 & 1 & 2 & 3 & 4 \\
\hline $\begin{array}{l}\text { 23. Using any medicines ON YOUR OWN, that is, } \\
\text { without a doctor's prescription? }\end{array}$ & 0 & 1 & 2 & 3 & 4 \\
\hline
\end{tabular}

Score: American Psychiatric Association. (2013). DSM-5 Self-Rated Level 1 Cross-Cutting Symptom Measure-Adult [Measurement instrument]. Retrieved from: https://www.psychiatry.org/psychiatrists/practice/dsm/educational-resources/assessment-measures\#Disorder

\section{References}

[1] American Psychiatric Association. (2013). DSM-5 Self-Rated Level 1 Cross-Cutting Symptom Measure-Adult [Measurement instrument]. Retrieved from: https://www.psychiatry.org/psychiatrists/practice/dsm/educatio nal-resources/assessment-measures\#Disorder

[2] Anderson, D. D., Gundersen, C. B., Banken, D. M., Halvorson, J. V., \& Schmutte, D. (1989). Undergraduate Role Players as "Clients" for Graduate Counseling Students. Teaching of

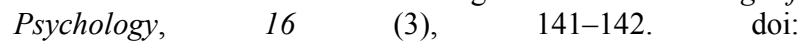
10.1207/s15328023top1603_11.

[3] Bados, A., \& García Grau, E. (2011). Habilidades terapéuticas. Publicación Electrónica Colección Objetos y Materiales Docentes (OMADO). Retrieved from: http://hdl.handle.net/2445/18382
[4] Ballon, B. C., Silver, I., \& Fidler, D. (2007). Headspace Theater: An Innovative Method for Experiential Learning of Psychiatric Symptomatology Using Modified Role-Playing and Improvisational Theater Techniques. Academi Psychiatry, 31, (5), 380-387. doi: 10.1176/appi.ap.31.5.380.

[5] Boyer, W. (2010). Empathy Development in Teacher Candidates. Early Childhood Education Journal, 38 (4), 313321. doi: 10.1007/s10643-010-0419-8.

[6] Clarke, P. B., Binkley, E. E., \& Andrews, S. M. (2017). Actors in the Classroom: The Dramatic Pedagogy Model of Counselor Education. Journal of Creativity in Mental Hea.lth, 12 (1), 129-145. doi: 10.1080/15401383.2016.1196156

[7] Cone, T. P, \& Cone, S. L. (1998). The Interdisciplinary Curriculum: Models for Developing a Learning Experience. Interdisciplinary Teaching Through Physical Education. Glassboro, NJ: Rowan University. Retrieved from: http://users.rowan.edu/ cone/interdisciplinarymodels.html. 
[8] Crane, A. (2012). Nomads of the Self: The Actor's Sense of Self and the Experience of Other Identities through Theatrical Roles. California Institute of Integral Studies, US: ProQuest Information \& Learning. 1-24.

[9] Cunico, L., Sartori, R., Marognolli, O., \& Meneghini, A. M. (2012). Developing empathy in nursing students: a cohort longitudinal study. Journal of Clinical Nursing, 21 (13-14), 2016-2025. doi: 10.1111/j.1365-2702.2012.04105. x.

[10] Gerdes, K. E., \& E. Segal. (2011). Importance of Empathy for Social Work Practice: Integrating New Science. Social Work, 56 (2, 2011), 141-148. doi: 10.1093/sw/56.2.141.

[11] Gillem, A. R. (1999). Teaching Counselor Trainees to Identify and Manage Countertransference through a Counseling Analogue. Teaching of Psychology, 26 (4), 274-276. doi: $10.1207 / \mathrm{s} 15328023$ top260407.

[12] Gilliland, K. (1982). Use of Drama Students as 'Clients' in Teaching Abnormal Psychology. Teaching of Psychology, 9 (2), 120-121. doi: 10.1207/s15328023top0902 26.

[13] Golding, C. (2009). Integrating the Disciplines: Successful Interdisciplinary Subjects. Centre for the Study of Higher Education. The University of Melbourne, 2, 22.

[14] Hinkle, M. S., \& Dean, L. M. (2017). Creativity in Teaching Case Conceptualization Skills: Role-play to Show the Interconnectedness of Domains. Journal of Creativity in Mental Health, 12 (3), 388-401. doi: 10.1080/15401383.2016.1249813.

[15] Lane, K. (1988). Using Actors as 'Clients' for an Interviewing Simulation in an Undergraduate Clinical Psychology Course. Teaching of Psychology, 15 (3), 162-164. doi: 10.1207/s15328023top1503_20.

[16] Low, K. G. (1996). Teaching an Undergraduate Seminar in Psychotherapy. Teaching of Psychology, 23 (2), 110-112. doi: 10.1207/s15328023top2302_10.
[17] Lyons, M. J., Bradley, C., \& White, J. (1984). Video Taping and Abnormal Psychology: Dramatized Clinical Interviews. Teaching of Psychology, 11 (1), 41-42. doi: 10.1207/s15328023top1101_12.

[18] Neumann, M., Edelhäuser, F., Tauschel, D., Fischer, M. R., Wirtz, M., Woopen, C., Scheffer, C. (2011). Empathy Decline and Its Reasons: A Systematic Review of Studies With Medical Students and Residents. Academic Medicine, 86 (8), 996-1009. doi: 10.1097/acm.0b013e318221e615.

[19] Pomerantz, A. M. (2003). Who Plays the Client? Collaborating with Theater Departments to Enhance Clinical Psychology Role-Play Training Exercises. Journal of Clinical Psychology, 59 (3), 363-368. doi: 10.1002/jclp.10079.

[20] Poorman, P. B. (2002). Biography and Role Playing: Fostering Empathy in Abnormal Psychology. Teaching of Psychology, 29 (1), 32-36. doi: 10.1207/S15328023TOP2901_08.

[21] Rodríguez, J. R., López, A. B., Escolano, A. F., García-Grau, E., García, C. S., Fort, G. B., Lluch, T., Pros, M. A. (2018). Peer Counselling Versus Role-Playing: Two Training Methods of Therapeutic Skills in Clinical Psychology. Psicothema, 30 (1), 21-26. doi: 10.7334/psicothema2016.286.

[22] Shem-Tov. (2011). Improvisational Teaching as Mode of Knowing. The Journal of Aesthetic Education, 45 (3), 103. doi: 10.5406/jaesteduc.45.3.0103.

[23] Weiss, A. R. (1986). Teaching Counseling and Psychotherapy Skills without Access to a Clinical Population: The Short Interview Method. Teaching of Psychology, 13 (3), 145-147. doi: 10.1207/s15328023top1303_12.

[24] Wolf, M. H., \& Miller, V. B. (1970). Theatre's Different Demands An Approach to the Classroom Teaching of Plays. Distributed by ERIC Clearinghouse. 